\title{
Heat Transfer Analysis in Cavity of Scroll Compressor Under Clearance Leakage Flow Based on Symlet Wavelet Finite Element Method
}

Bin Zhao ( $\sim$ zbzbz0203288@163.com )

liaoning shihua university

Haoyang Song

liaoning shihua university

Diankui Gao

liaoning shihua university

Lizhi Xu

Liaoning Shihua University: Liaoning University of Petroleum and Chemical Technology

Original Article

Keywords: Scroll compressor, Leakage flow, Symlet wavelet 10 finite element, large eddy simulation, clearance

Posted Date: December 28th, 2020

DOl: https://doi.org/10.21203/rs.3.rs-134824/v1

License: (9) (1) This work is licensed under a Creative Commons Attribution 4.0 International License. Read Full License 


\title{
Heat Transfer Analysis in Cavity of Scroll Compressor under Clearance Leakage Flow Based on Symlet Wavelet Finite Element Method
}

\author{
Bin zhao*, Haoyang Song, Diankui Gao, Lizhi Xu \\ (1 School of Mechanical Engineering, Liaoning Shihua University, Fushun Liaoning, 113001, \\ China) \\ Telephone/fax number: +86-024-56865042 \\ E-mail:zbzbz0203288@163.com
}

\begin{abstract}
In order to improve the computational precision and efficiency of heat transfer of cavity medium of scroll compressor, the Symlet wavelet 10 finite element model is constructed by using the Symlet wavelet 10 function as interpolation function. The heat transfer model of cavity medium of scroll compressor under leakage flow is constructed based on large eddy simulation technology. Heat transfer analysis of cavity medium of scroll compressor is analyzed based on theoretical and experimental analysis. Results show that the Symlet wavelet 10 finite element model has higher precision and higher efficiency than the other two simulations. In addition, the influences of axis meshing clearance and radial meshing clearance on temperature of cavity medium of scroll compressor are discussed, the temperature of cavity medium of scroll compressor increases with axis meshing clearance and radial meshing clearance. The theoretical results can provide the favorable guidance for optimal design and operation of scroll compressor.
\end{abstract}

Key words: Scroll compressor; Leakage flow; Symlet wavelet 10 finite element; large eddy simulation; clearance

\section{Nomenclature}

$a$ and $b$ discrete values

$A$ and $B$ frame limits

$\stackrel{\mu}{c}=\left(c_{0}, \mathrm{~K}, c_{-(N-2)}\right)$ Symlet wavelet coefficient vector

$c_{p}$ specific heat capacity

$C$ model coefficient

$e$ Symlet wavelet finite element

$\tilde{h}_{c}$ given convective heat transfer coefficient on third boundary condition

$H$ heat capacity matrix

$L_{i j}$ turbulent stress of solvable size Interaction

$i, j \quad x, y$ and $z$ coordinate 
$k_{x}, k_{y}$ and $k_{z}$ thermal conductivity

$K$ heat conduction matrix

$M_{i j}$ variable relating to filtering scale and shear rate tensor

$n_{x}, n_{y}$ and $n_{z}$ outward cosines of first boundary condition

$p$ pressure of medium

$\bar{p}$ pressure after filtering processing

$q_{j}$ sub-grid thermal flux

$\tilde{q}_{f}(t)$ given heat flux density on second boundary condition

$Q=Q(x, y, z, t)$ internal heat source of medium in cavity

$R$ temperature load vector

$S$ surface of Symlet wavelet finite element

$\overline{S_{i j}}$ deformation rate tensor on solvable scale

$t$ time

$T$ temperature of medium

$T_{b}(t)$ given temperature on first boundary condition

$T_{c} \quad$ environmental temperature

$u_{i}$ velocity in $i$ coordinate direction

$\bar{u}_{i}$ velocity after filtering processing in $i$ coordinate direction

$\bar{u}_{j}$ velocity after filtering processing in $j$ coordinate direction

$V \quad$ volume of Symlet wavelet finite element

$\rho$ density of medium

$\bar{\rho}$ density of medium after filtering processing

$\mu$ kinetic viscosity of medium

$\mu_{s}$ sub-grid eddy viscosity coefficient

$\lambda$ thermal conductivity of medium

$\tau_{i j}$ sub-grid scale stress

$\psi$ function

$\Phi \quad$ Symlet wavelet basis function

$\Delta$ filtering scale. 


\section{Introduction}

The scroll compressor is the latest displacement compressor, which has the merits of small occupied space, light weight, high compression efficiency and compact layout. The scroll compressor has established the refrigeration compressor markets depending on variable capacity adjustment technology. Currently the scroll compressor has been going in the direction of broadening the frozen and refrigerated food and heat pump industries. Developing the scroll compressor with better performance and more compact structure is becoming one hot topic of research, where the heat transfer research of medium in cavity of scroll compressor can provide the favorable basis for optimal design of the scroll compressor. Research on heat transfer mechanism of scroll compressor has been paid more and more attention by many scientists.

Marco C. Diniz et al. proposed a thermal model to predict the temperature in different chambers and components inside scroll compressors, which was coupled to a thermodynamic model of the compression cycle and then applied to simulate the compressor performance under different conditions [1]. Evandro L.L. Pereira and Cesar J. Deschamps proposed an improved heat transfer model inside the suction and compression chambers of scroll compressors, and developed a algorithm of realizing the computational mesh automatically for each orbiting angle [2]. Alireza Zendehboudi and Afshin Tatar proposed a Hybrid-Adaptive Neuro Fuzzy Inference System of estimating the discharge temperature of scroll compressor, and the correctness of the proposed model is verified through experimental verification [3]. Domenique R. Lumpkin et al. established compressor maps for a single-speed R-407C scroll compressor with two-phase injection and vapor-injected compression, and presented a dimensionless PI correlation for mapping the refrigeration discharge temperature and the heat loss ratio for these compressor maps [4]. Luis Carlos Mendoza et al. carried out experimental and theoretical investigations about co-rotation scroll compressor, and the influence of input variables on the heat transfer of scroll compressor was studied, the exhaust temperature was predicted [5].

The scroll compressor has a leak between working chamber and outside and between working chambers, and the leakage is a main factor of affecting performance of scroll compressor, therefore it is necessary to study the effect of leakage on heat transfer of cavity medium of scroll compressor. The leakage mechanism of scroll compressor has been widely investigated, and many accomplishments have been obtained. Morini MirkoPavan studied the adaptation of a scroll compressor to be used as an expander in a micro ORC system based on computational fluid dynamics methodology, and the relationship between the volumetric efficiency of the scroll compressor and the magnitude of the flank gap was obtained [6]. Singh Simarpreet et al. The fluid flow characteristics of refrigerant in a scroll compressor based on CFD method, results showed that the internal leakage of refrigerant could increase the overall efficiency of the scroll compressor [7]. Rak, Józef et al. proposed a numerical spatial scroll compressor model with a mesh generation procedure, and carried out calculations for different value of the radial clearance between scroll wraps [8]. Burmistrov A. et al. proposed a model of working process of oil free scroll vacuum pump to study the effect of leakage and heat transfer on pumping characteristics, the model considered the change of clearance due to thermal deformations [9]. Mendoza Luis Carlos et al. proposed a new leakage model considering the deformation of the flanks and the scroll involutes, and the exhaust temperature, mechanical power and mass flow rate were predicted based on proposed model [10]. The leakage flow and heat transfer of scroll compressor has strong coupling relation, and has remarkable impact on heat transfer rules of cavity, and this 
process is very complex, the traditional model tends to biggish error, therefore the effective model can be used to analyzed heat transfer process of cavity of scroll compressor considering clearance leakage flow.

The current research on scroll compressor are still focus on influence of leakage flow on performance of it, and few studies on influence of leakage flow on heat transfer of it have been conducted. It is necessary to study the influence of leakage flow on the heat transfer of cavity medium of scroll compressor. The heat transfer process of cavity medium of scroll compressor under leakage flow has strong nonlinear features, therefore an advanced numerical calculation method should be selected to carried out heat transfer analysis of cavity medium under leakage flow. The wavelet finite element method uses wavelet function or scale function as interpolating function to construct the wavelet finite element. The wavelet has been applied in many fields successfully, Fábio M.Bayer et al. introduced an adaptive filtering process based on shrinking wavelet coefficients, and simulation showed that the proposed method outperformed several well-known denoising schemes [11]. Mariantonia Cotronei et al. gave a generalized shearlet construction for arbitrary dimensions and arbitrary scalings for which the filterbank construction ensures the existence of an orthogonal wavelet analysis [12]. Max Budninskiy et al. propsoed the first construction of operator-adapted wavelets for finite-element differential forms, which can provide arbitrary smoothness orders of basis functions and wavelets and can accommodate linear differential constraints [13], therefore the wavelet finite element method can randomly change the analysis scale according to the requirements. The wavelet finite element method uses less analysis scale to process solution region with larger gradient, and use bigger analysis scale to process solution region with less gradient, and then the computation precision and efficiency can be improved [14-16]. In recent years, people have conducted more thorough research on the wavelet finite element method,and achieved many fruits. Samaratunga Dulip et al. proposed ultrasonic guided wave propagation model in stiffened composite panels based on wavelet spectral finite element method, which can analyze the transient response resulting from loads with short time duration [17]. Azdoud Yan et al. carried out micro-mechanical analysis of poly-crystalline micro structures of metals and alloys based on wavelet-enriched adaptive crystal plasticity finite element model. Various validation tests were carried out to verify the convergence rates and computational efficiency of the proposed model [18]. Ashory Mohammad-Reza et al. studied the damage identification in composite laminates based on a hybrid method with wavelet transform and finite element updating, and the accuracy of identifying the damage parameters was improved based on the proposed method [19]. The wavelet is biorthogonal, compact supported, and approximate symmetric among the numerous wavelet bases, the Symlet wavelet has linear phase, smooth and simple calculation properties [20], therefore the Symlet wavelt basis function or scale function can be used as interpolation function to construct the Symlet wavelet finite element model to improve the computational effectiveness.

This paper is organized in the following way. In Section 2, the heat transfer model of medium in cavity of scroll compressor under leakage flow is constructed. In Section 3,the heat transfer Symlet wavelet finite element model of medium in cavity of scroll compressor under leakage flow is established. In Section 4, the heat transfer analysis of medium in cavity of scroll compressor under leakage-heat coupling is carried out. Finally, the important conclusions and future researching work are derived.

\section{Heat transfer model of medium in cavity of scroll compressor under leakage flow}


2.1 Conservation equations of clearance leakage-heat coupling

(1) Conservation equation

The clearance leakage flow of scroll compressor must obey three conservation equations, which conclude mass conservation equation, momentum conservation equation and energy conservation equation.

The mass conservation equation is expressed by [21]

$$
\frac{\partial \rho}{\partial t}+\frac{\partial\left(\rho u_{i}\right)}{\partial x_{i}}=0
$$

where $u_{i}$ denotes the velocity in $i$ coordinate direction, $i$ denotes $x, y$ and $z$ coordinate.

The momentum conservation equation is expressed by [22]

$$
\frac{\partial\left(\rho u_{i}\right)}{\partial t}+\frac{\partial\left(\rho u_{i} u_{j}\right)}{\partial x_{j}}=\frac{\partial}{\partial x_{j}}\left(\mu \frac{\partial u_{i}}{\partial x_{j}}\right)-\frac{\partial p}{\partial x_{j}},
$$

where $\rho$ denotes the density of medium, $\mu$ denotes the kinetic viscosity of medium, $p$ denotes the pressure of medium.

The energy conservation equation is expressed by [23]

$$
\frac{\partial T}{\partial t}+\frac{\partial\left(\rho u_{j} T\right)}{\partial x_{j}}=\frac{\partial}{\partial x_{i}}\left(\frac{\lambda}{c_{p}} \frac{\partial T}{\partial x_{j}}\right),
$$

where $c_{p}$ denotes the specific heat capacity, $T$ denotes the temperature of medium, $\lambda$ denotes the thermal conductivity of medium.

(2) Large eddy simulation model

The clearance leakage flow is affected by boundary layer, main stream and second flow of channel, and is impacted by unsteady aerodynamic characteristic formed periodic exhaust process of scroll compressor. Therefore the leakage flow in clearance of scroll compressor can be considered as the turbulent flow, the large eddy simulation model is used to describe the clearance leakage flow. The filtering processing is carried out for the conservation equations [24].

The mass conservation equation of large eddy simulation is expressed by

$$
\frac{\partial \bar{\rho}}{\partial t}+\frac{\partial\left(\bar{\rho} \bar{u}_{i}\right)}{\partial x_{i}}=0
$$

where $\bar{\rho}$ denotes the density of medium after filtering processing, $\bar{u}_{i}$ denotes the velocity after filtering processing in $i$ coordinate direction.

The momentum conservation equation of large eddy simulation is expressed by

$$
\frac{\partial\left(\bar{\rho} \bar{u}_{i}\right)}{\partial t}+\frac{\partial\left(\bar{\rho} \bar{u}_{i} \bar{u}_{j}\right)}{\partial x_{j}}=\frac{\partial}{\partial x_{j}}\left(\mu \frac{\partial \bar{u}_{i}}{\partial x_{j}}\right)-\frac{\partial \bar{p}}{\partial x_{j}}-\frac{\partial \tau_{i j}}{\partial x_{j}},
$$

where $\bar{u}_{j}$ denotes the velocity after filtering processing in $j$ coordinate direction, $j$ denotes 
$x, y$ and $z$ coordinate, $\bar{p}$ denotes the pressure after filtering processing, $\tau_{i j}$ denotes the sub-grid scale stress, which is calculated by [25]

$$
\tau_{i j}=-2 \mu_{s} \overline{S_{i j}}+\frac{1}{3} \tau_{k k} \delta_{i j}
$$

where $\mu_{s}$ denotes the sub-grid eddy viscosity coefficient, which is calculated by [26]

$$
\mu_{s}=\rho C_{d} \Delta^{2}\left|\bar{S}_{i j}\right|
$$

where $C_{d}=\frac{<L_{i j} M_{i j}>}{<M_{i j} M_{i j}>}$

where $L_{i j}$ denotes the turbulent stress of solvable size Interaction, $M_{i j}$ denotes variable relating to filtering scale and shear rate tensor, $\Delta$ denotes the filtering scale.

$\overline{S_{i j}}$ denotes deformation rate tensor on solvable scale, which is expressed by

$$
\bar{S}_{i j}=\frac{1}{2}\left(\frac{\partial \bar{u}_{i}}{\partial x_{j}}+\frac{\partial \bar{u}_{j}}{\partial x_{i}}\right),
$$

The energy conservation equation of large eddy simulation is expressed by

$$
\frac{\partial \bar{T}}{\partial t}+\frac{\partial\left(\rho \bar{u}_{j} \bar{T}\right)}{\partial x_{j}}=\frac{\partial}{\partial x_{i}}\left(\frac{\lambda}{c_{p}} \frac{\partial \bar{T}}{\partial x_{j}}\right)-\frac{\partial q_{j}}{\partial x_{j}}
$$

where $q_{j}$ denotes the sub-grid thermal flux, $q_{j}=\overline{u_{j} T}-\bar{u}_{j} \bar{T}$.

The linear eddy viscosity model is used to combine the anisotropic part of sub-grid stress and strain rate on minimum resolution scale, and the corresponding mathematical model is expressed by [27]

$$
\tau_{i j}-\frac{1}{3} \tau_{k k} \delta_{i j}=2 v_{t} \bar{S}_{i j}=2 C \Delta^{2} \sqrt{2 \bar{S}_{i j} \bar{S}_{i j}} \bar{S}_{i j}
$$

where $C$ denotes the model coefficient, $C=0.09$.

2.2 Heat transfer model of medium in cavity of scroll compressor

The transient heat control equation of medium in cavity of scroll compressor is expressed by [28]

$$
\rho c_{p} \frac{\partial T^{\prime}}{\partial t}-\frac{\partial}{\partial x}\left(k_{x} \frac{\partial T^{\prime}}{\partial x}\right)-\frac{\partial}{\partial y}\left(k_{y} \frac{\partial T^{\prime}}{\partial y}\right)-\frac{\partial}{\partial z}\left(k_{z} \frac{\partial T^{\prime}}{\partial z}\right)-\rho Q=0,
$$

where $k_{x}, k_{y}$ and $k_{z}$ denote the thermal conductivity, $W /(m \cdot K), Q=Q(x, y, z, t)$ denotes the internal heat source of medium in cavity; $t$ denotes time, $s$.

The boundary conditions of heat transfer model are listed as follows:

(1) First boundary condition $\left(\Gamma_{1}\right): T^{\prime}(x, y, z, t)=T_{b}(t)$, 
(2) Second boundary condition $\left(\Gamma_{2}\right): k_{x} \frac{\partial T^{\prime}}{\partial x} n_{x}+k_{y} \frac{\partial T^{\prime}}{\partial y} n_{y}+k_{z} \frac{\partial T^{\prime}}{\partial z} n_{z}=\tilde{q}_{f}(t)$,

(3) Third boundary condition $\left(\Gamma_{3}\right): k_{x} \frac{\partial T^{\prime}}{\partial x} n_{x}+k_{y} \frac{\partial T^{\prime}}{\partial y} n_{y}+k_{z} \frac{\partial T^{\prime}}{\partial z} n_{z}=\tilde{h}_{c}\left(T_{c}-T^{\prime}\right)$,

where $n_{x}, n_{y}$ and $n_{z}$ are outward cosines of first boundary condition; $T_{b}(t)$ denotes the given temperature on first boundary condition $\Gamma_{1}, K ; \tilde{q}_{f}(t)$ denotes the given heat flux density on second boundary condition $\Gamma_{2}, W / m^{2} ; \tilde{h}_{c}$ denotes the given convective heat transfer coefficient on third boundary condition $\Gamma_{3}, W /\left(m^{2} \cdot K\right) ; T_{c}$ denotes the environmental temperature, $K$.

3 Heat transfer Symlet wavelet finite element model of medium in cavity of scroll compressor under leakage flow

The heat transfer model of cavity of scroll compressor under leakage flow can be obtained based on clearance leakage-heat transfer coupling model constructed in the section 2 . The clearance leakage flow-heat coupling and heat transfer of cavity of scroll compressor can all be analyzed based on proposed beamlet finite element model.

\subsection{Basic characteristics of wavelet}

The Symlet wavelet was constructed by Daubechies, which can improve the symmetry of wavelet function while maintaining the simplicity of Daubechies wavelet, so that the Symlet wavelet beet meets the requirements of nonlinear analysis.

The function $\psi$ satisfies the condition $\int_{-\infty}^{+\infty} \psi(x) d x=0$, a function can be generated by translation and dilatation that is expressed by [29]

$$
\psi_{a, b}(x)=|a|^{-1 / 2} \psi\left(\frac{x-b}{a}\right),(a, b \in R, a \neq 0),
$$

For arbitrary function $f \in L^{2}(R)$, if $\psi \in L^{2}(R)$, the continuous wavelet transform of $f(t)$ is defined by

$$
\Psi_{f}(a, b)=\int_{-\infty}^{+\infty} \overline{\psi_{a, b}(t)} f(t) d t,
$$

When $a$ and $b$ are discrete values, $a=a_{0}^{m}, m \in Z, b=n b_{0} a_{0}^{m}, n \in Z$, the discrete wavelet transform of $f(t)$ are defined by [30]

$$
C_{m, n}(f)=\int_{-\infty}^{+\infty} \overline{\psi_{m, n}(t)} f(t) d t
$$

where $\psi_{m, n}(t)=a^{-m / 2} \psi\left(a_{0}^{-m} t-n b_{0}\right), a_{0}>1, b_{0} \neq 0$. The function $\left\{\psi_{i}\right\}_{j \in J}$ in Hillbert space is known as a frame. If there are $0<A, B<\infty$ make following conditions true 
for all $f \in H$,

$$
A\|f\|^{2} \leq \sum_{j \in J}\left|<f, \psi_{j}>\right|^{2} \leq B\|f\|^{2},
$$

where $A$ and $B$ are frame limits, if they are equal, the two frames are compact frames. When $\left\{\psi_{m, n}\right\}, m, n \in Z$ is a frame of $L^{2}(R), f(t)$ is expanded to wavelet coefficients by using discrete wavelet transform as coefficient, and the corresponding expression is listed as follows [31]:

$$
f(t)=\sum_{m, n} C_{m, n}(f) \psi_{m, n}(t),
$$

The Symlet wavelet function and its scale function are shown in figure 1 and figure 2.

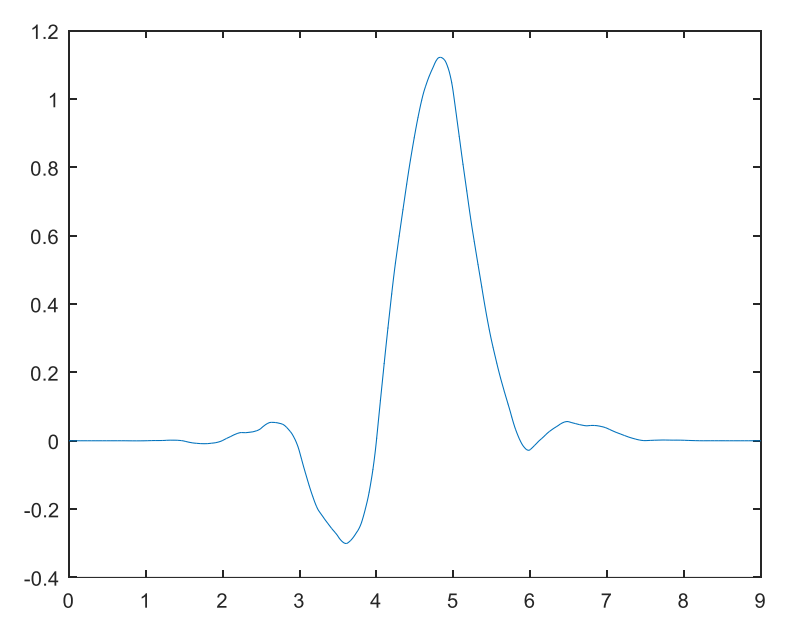

Figure 1 Symlet wavelet function

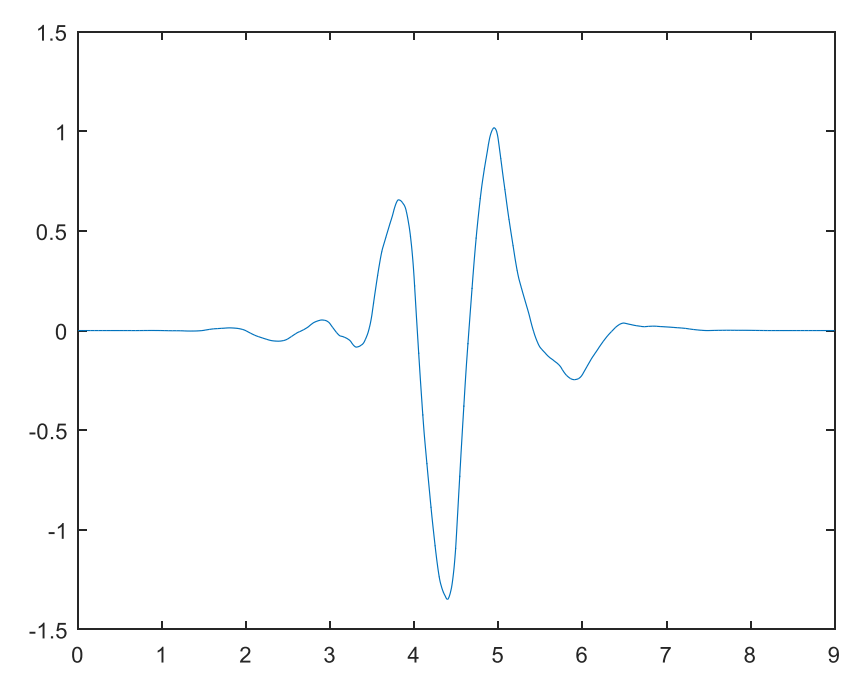

Figure 2 Symlet wavelet scale function

3.2 Beamlet finite element model of clearance leakage-heat coupling

The clearance leakage flow equation (2) is dispersed based on finite element method, the equation (2) is expanded to a Taylor series, and then the time derivative can be replaced by space 
derivative.

The processed momentum conservation equation (2) based on Euler-Taylor-Galerkin finite element method can be changed to the following expression [32]:

$$
\begin{gathered}
\int_{V_{e}}\left(1-\frac{1}{2} \Delta t \mu \frac{\partial^{2}}{\partial x_{i} \partial x_{i}}\right) \frac{u_{i}^{n+1}-u_{i}^{n}}{\Delta t} \Phi_{I}(b) d V=\int_{V_{e}}\left(1-\frac{1}{2} \Delta t u_{j}^{n} \frac{\partial}{\partial x_{j}}\right)\left(-u_{j}^{n} \frac{\partial u_{i}^{n}}{\partial x_{j}}-\frac{\partial p^{n}}{\partial x_{i}}+\mu \frac{\partial^{2} u_{i}^{n}}{\partial x_{j} \partial x_{j}}\right) \Phi_{I}(b) d V \\
+\int_{V_{e}} \frac{1}{2} \Delta t\left[\left(u_{k}^{n} \frac{\partial u_{j}^{n}}{\Delta x_{k}}+\frac{\partial p^{n}}{\partial x_{j}}-\mu \frac{\partial^{2} u_{j}^{n}}{\partial x_{k} \partial x_{k}}\right) \frac{\partial u_{i}^{n}}{\partial x_{j}}-\left(\frac{\partial p^{n}}{\partial x_{i}}-\frac{\partial p^{n-1}}{\partial x_{i}}\right) \frac{1}{\Delta t}\right] \Phi_{I}(b) d V,(21)
\end{gathered}
$$

The Symlet wavelet basis velocity field function is expressed by [33]

$$
\begin{aligned}
& \rho_{e}=\Phi_{J}\left[\rho_{J}^{n}\right]^{e}, \\
& \mathfrak{r}^{e}=\Phi_{J}\left[f_{J}^{n}\right]^{e},
\end{aligned}
$$

where $\Phi$ denotes Symlet wavelet basis function.

The following expression can be obtained through substituting expression (22) into expression (21):

$$
\begin{aligned}
& A_{I J}^{e}\left[\rho_{J}^{\rho_{n}+1}\right]^{e}=\left(B_{I J}^{e}\left[\rho_{J}^{\rho_{I}}\right]^{e}+C_{I J}^{e}\left[u_{J}^{\rho_{n}}\right]^{e}+P_{I J}^{e}+F_{I}^{e}\right) \Delta t+A_{I J}^{e}\left[\rho_{J}^{n}\right]^{e}, \\
& A_{I J}^{e}=\int_{V_{e}} \Phi_{I} T_{f J} d V+\int_{V_{e}} \frac{1}{2} \mu \Delta t \frac{\partial \Phi_{I}}{\partial x_{i}} \frac{\partial \Phi_{J}}{\partial x_{i}} d V, \\
& B_{I J}^{e}=\int_{V_{e}}\left(-\Phi_{I} u_{j} \frac{\partial \Phi_{I}}{\partial x_{j}}-\mu \frac{\partial \Phi_{I}}{\partial x_{i}} \frac{\partial \Phi_{J}}{\partial x_{i}}\right) d V-\int_{V_{e}} \frac{1}{2} \Delta t u_{j} u_{j} \frac{\partial \Phi_{I}}{\partial x_{j}} \frac{\partial \Phi_{J}}{\partial x_{j}} d V, \\
& C_{I J}^{e}=\int_{V_{e}} \frac{1}{2} \Delta t \Phi_{I}\left[\left(u_{k} \frac{\partial u_{j}}{\partial x_{k}}+\frac{\partial p}{\partial x_{j}}-\mu \frac{\partial^{2} u_{j}}{\partial x_{k} \partial x_{k}}\right) \frac{\partial \Phi_{J}}{\partial x_{j}}\right] d V, \\
& P_{I J}^{e}=\int_{V_{e}}\left[-\frac{1}{2}\left(\frac{\partial p^{n}}{\partial x_{i}}-\frac{\partial p^{n-1}}{\partial x_{i}}\right)\right] \Phi_{I} d V, \\
& F_{I}^{e}=\int_{V_{e}}\left(\Phi_{I}+\frac{1}{2} \Delta t u_{j} \frac{\partial \Phi_{I}}{\partial x_{j}}\right)\left(-\frac{\partial p}{\partial x_{i}}\right) d V,
\end{aligned}
$$

Finite element equations of all elements in computational domain are superimposed to construct the global finite element equation that is expressed by [34]

$$
A u^{\rho_{1}}=\left(B u^{\rho_{n}}+C{u^{n}}+P+F\right) \Delta t+A{u_{n}},
$$

3.3 Heat transfer finite element model of medium in cavity of scroll compressor

The Symlet wavelet function is used as the interpolation function, and the temperature function is defined by

$$
\stackrel{\mu}{T}=\Phi c
$$


where $\stackrel{\mu}{c}=\left(c_{0}, \mathrm{~K}, c_{-(N-2)}\right)$ is the Symlet wavelet coefficient vector.

Equivalent integral form of 3D heat conduction can be obtained, which is expressed by

$$
\begin{gathered}
\int_{V_{e}}\left[\delta T^{\prime}\left(\rho c_{\mathrm{T}} \frac{\partial T^{\prime}}{\partial t}\right)-\frac{\partial \delta T^{\prime}}{\partial x}\left(k_{x} \frac{\partial T^{\prime}}{\partial x}\right)-\frac{\partial \delta T^{\prime}}{\partial y}\left(k_{y} \frac{\partial T^{\prime}}{\partial y}\right)-\frac{\partial \delta T^{\prime}}{\partial z}\left(k_{z} \frac{\partial T^{\prime}}{\partial z}\right)-\delta T^{\prime} \rho Q\right] d V \\
-\int_{\Gamma_{2 \mathrm{e}}} \delta T^{\prime} q d S-\int_{\Gamma_{3 \mathrm{e}}} \delta T h\left(T_{c}-T^{\prime}\right) d S=0
\end{gathered}
$$

where $e$ denotes the Symlet wavelet finite element, $V$ denotes the volume of Symlet wavelet finite element, $S$ denotes the surface of Symlet wavelet finite element.

Plugging expression (23) into expression (32) and considering the randomness of $\delta T^{\prime}$, the Symlet wavelet finite element model is acquired that is expressed by [35]

$$
H \frac{d T^{\prime}}{d t}+K T^{\prime}=R
$$

where $H$ is the heat capacity matrix, $K$ is heat conduction matrix, $R$ is the temperature load vector.

$$
\begin{aligned}
& H_{i j}=\sum H_{i j}^{e}, \\
& K_{i j}=\sum K_{i j}^{e}, \\
& F_{i j}=\sum F_{i j}^{e},
\end{aligned}
$$

where every element matrix in expressions (34)-(36) is expressed by

$$
\begin{aligned}
& H_{i j}^{e}=\int_{V_{e}} \rho c_{T} \Phi_{I} \Phi_{J} d V \\
& K_{i j}^{e}=\int_{V_{e}}\left(k_{x} \frac{\partial \Phi_{I}}{\partial x} \frac{\partial \Phi_{J}}{\partial x}+k_{y} \frac{\partial \Phi_{I}}{\partial y} \frac{\partial \Phi_{J}}{\partial y}+k_{z} \frac{\partial \Phi_{I}}{\partial z} \frac{\partial \Phi_{J}}{\partial z}\right) d V+\int_{\Gamma_{3 e}} h \Phi_{I} \Phi_{J} d S, \\
& R_{i}^{e}=\int_{V_{e}} Q \Phi_{I} d V+\int_{\Gamma_{2 e}} q \Phi_{I} d S+\int_{\Gamma_{3 e}} h T_{c} \Phi_{I} d S
\end{aligned}
$$

4 Heat transfer analysis of medium in cavity of scroll compressor under leakage-heat coupling

In order to verify the accuracy of the proposed Symlet wavelet finite element model, a case with exact solution is used to carry comparison analysis. A cylinder that is shown in figure 3 is heated from a uniform temperature, temperature of internal surface $(r=a, a=10 m)$ of the cylinder increases $10^{\circ} \mathrm{C}$, temperature of outer surface $(r=b, b=20 \mathrm{~m})$ of the cylinder increases $20^{\circ} \mathrm{C}$, and there is no hot source.

The specifications of the used computer are set as follows: the CPU is 64bit, it has 2 core, the 
memory is $1 \mathrm{G}$, the resolution ratio is 1680 , and the memory is $8 \mathrm{G}$.
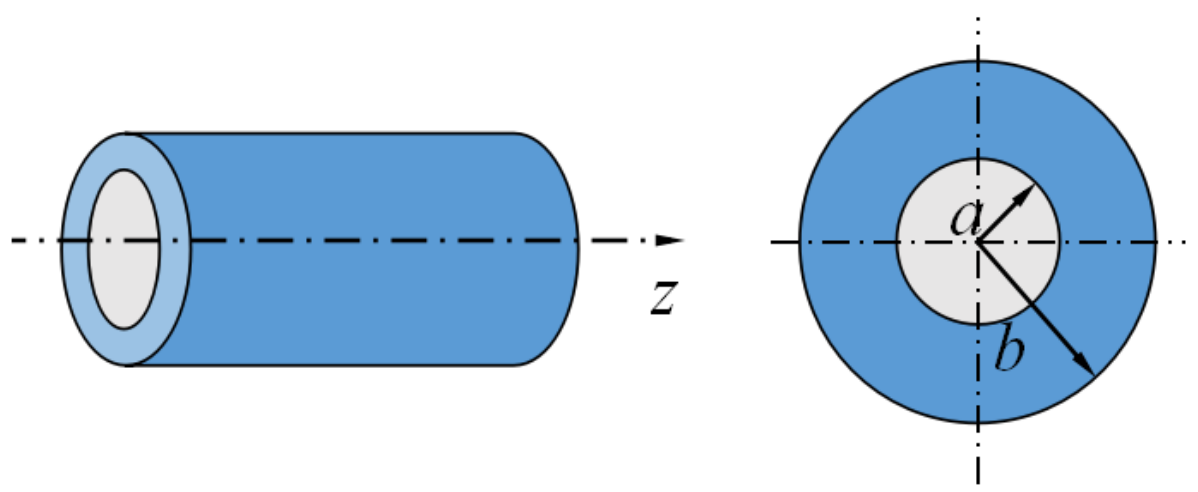

Figure 3 Diagram of cylinder

The temperature along radial direction is calculated by theoretic formulas and Symlet wavelet finite element method respectively. The comparison results are listed in table 1.

Table 1 Comparison results of temperature distribution of cylinder along radial direction

\begin{tabular}{|c|c|c|c|}
\hline & Exact solution $/{ }^{\circ} \mathrm{C}$ & $\begin{array}{c}\text { Symlet wavelet finite } \\
\text { element solution } /{ }^{\circ} \mathrm{C}\end{array}$ & Error/\% \\
\hline$r=12 \mathrm{~mm}$ & 12.63 & 13.03 & $3.2 \%$ \\
\hline$r=14 \mathrm{~mm}$ & 14.85 & 14.96 & $2.4 \%$ \\
\hline$r=16 \mathrm{~mm}$ & 16.78 & 17.16 & $2.3 \%$ \\
\hline$r=18 \mathrm{~mm}$ & 18.48 & 18.95 & $2.5 \%$ \\
\hline
\end{tabular}

As seen from table 2, the temperature solution from Symlet wavelet finite element method is close to exact solution from theoretical model, the calculating errors range from $2.3 \%$ to $3.2 \%$ when the value of $r$ is different. Therefore the Symlet wavelet finite element method can obtain high computing precision.

The heat transfer analysis of cavity medium of a scroll compressor under leakage flow is carried out based on the Symlet wavelet finite element model. The suction pressure of scroll compressor is $0.15 \mathrm{MPa}$, the exhaust pressure of scroll compressor is $0.65 \mathrm{MPa}$, the suction temperature is $293 \mathrm{~K}$, the basic circle radius is $2.8 \mathrm{~mm}$, the number of scroll circles is 3.886 , the scroll pitch is $17.26 \mathrm{~mm}$, the rotating radius is $5.86 \mathrm{~mm}$, the thickness of scroll plate is $3.56 \mathrm{~mm}$, the height of the scroll wrap is $45 \mathrm{~mm}$, the occurrence angle of involute is $0.65 \mathrm{rad}$, the termination angle of the scroll teeth is $2.5 \mathrm{rad}$, and the compression ratio is 4.77 . The axial meshing clearance is $0.6 \mathrm{~mm}$, the radial meshing clearance is $0.3 \mathrm{~mm}$. 
The Symlet wavelets (1-16) are selected to constructed the Symlet wavelet finite element models. The computational error and computational time of different Symlet wavelets are shown in figure 4. As seen from figure 4, computational error decreases with order, while the computational time increases with order, the Symlet wavelet 10 finite element model can obtain the best analysis effect, which has relatively small calculating errors and calculating time. Therefore the Symlet wavelet 10 finite element is applied to carry out heat transfer of cavity medium of scroll compressor.

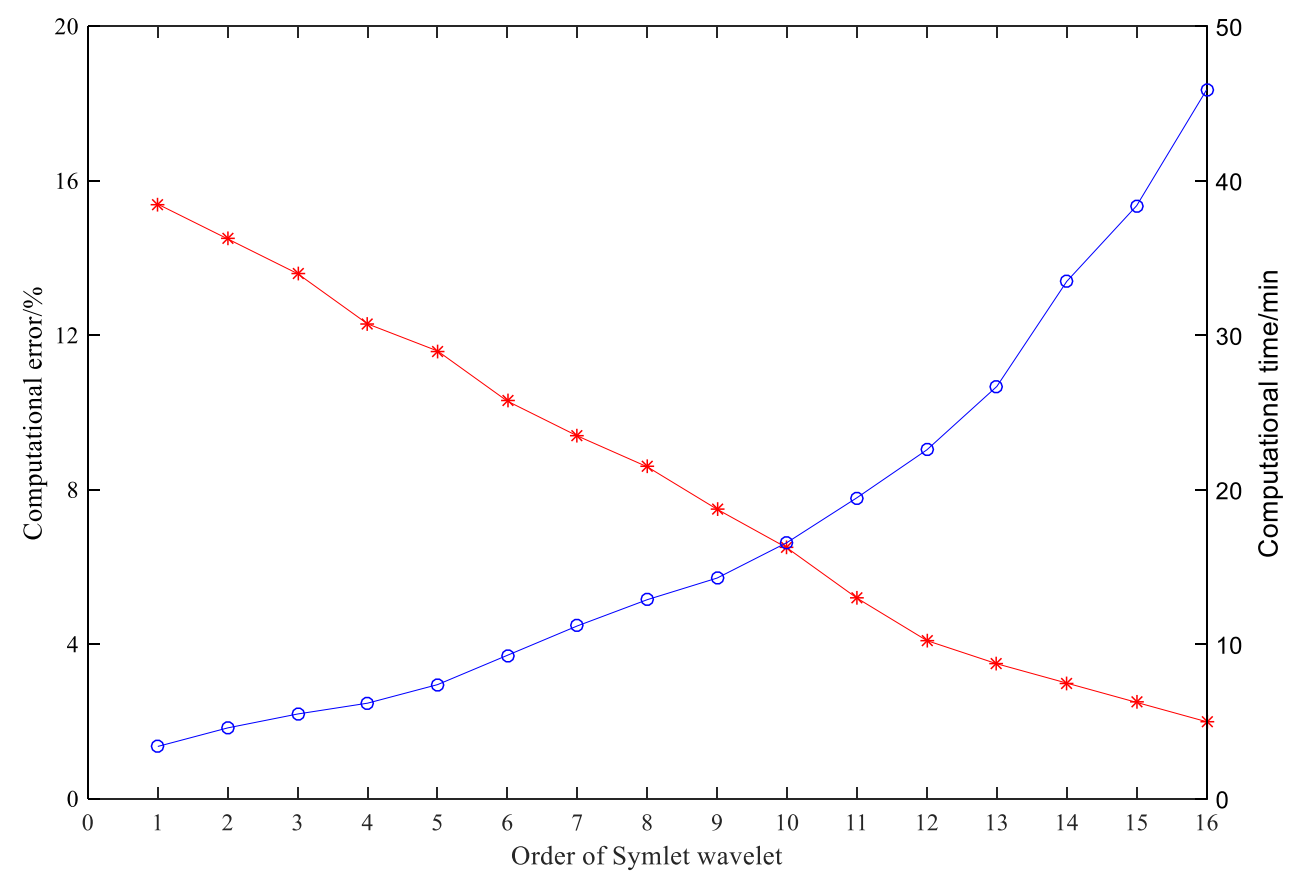

Figure 4 Computational error and time of different Symlet wavelet function

In order to verify the effectiveness of the proposed Symlet wavelet 10 finite element model (SW10FEM), the traditional finite element method (TFEM), and the Daubechies finite element method (DFEM) are also applied to carry out heat transfer analysis of the cavity medium for the same scroll compressor. Mesh generation situations of the solution region are listed in table 2.

Table 2 Mesh division situation of the solution region

\begin{tabular}{|c|c|c|}
\hline Method & $\begin{array}{c}\text { Number of } \\
\text { elements }\end{array}$ & Number of nodes \\
\hline TFEM & 96337 & 217732 \\
\hline DFEM & 6893 & 12886 \\
\hline SW10FEM & 4955 & 8961 \\
\hline
\end{tabular}

The effect of clearance flow on average temperature of cavity of scroll compressor is analyzed based on TFEM, DFEM and SW10FEM respectively, in order to verify the correctness of simulation result, the temperature of cavity medium of scroll compressor is also measured by temperature sensor. The testing system is shown in figure 5 .

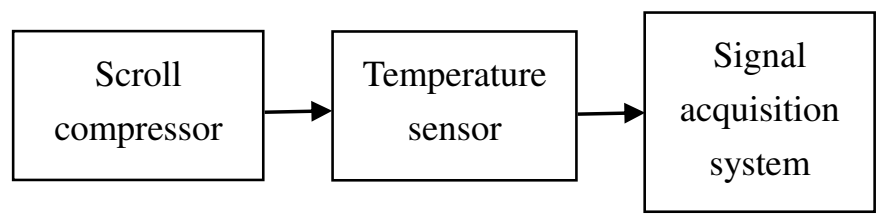


Figure 5 Temperature testing system of scroll compressor

The comparison results are shown in figure 6. As seen from figure 6, the temperature of cavity medium of scroll compressor obtained from SW10FEM is closer to testing value than other two simulation methods, the temperature of the cavity medium obtained from DFEM is slightly higher than that obtained from SW10FEM, and the solutions obtained from TFEM is lowest, therefore the SW10FEM has higher computational precision than other two methods.

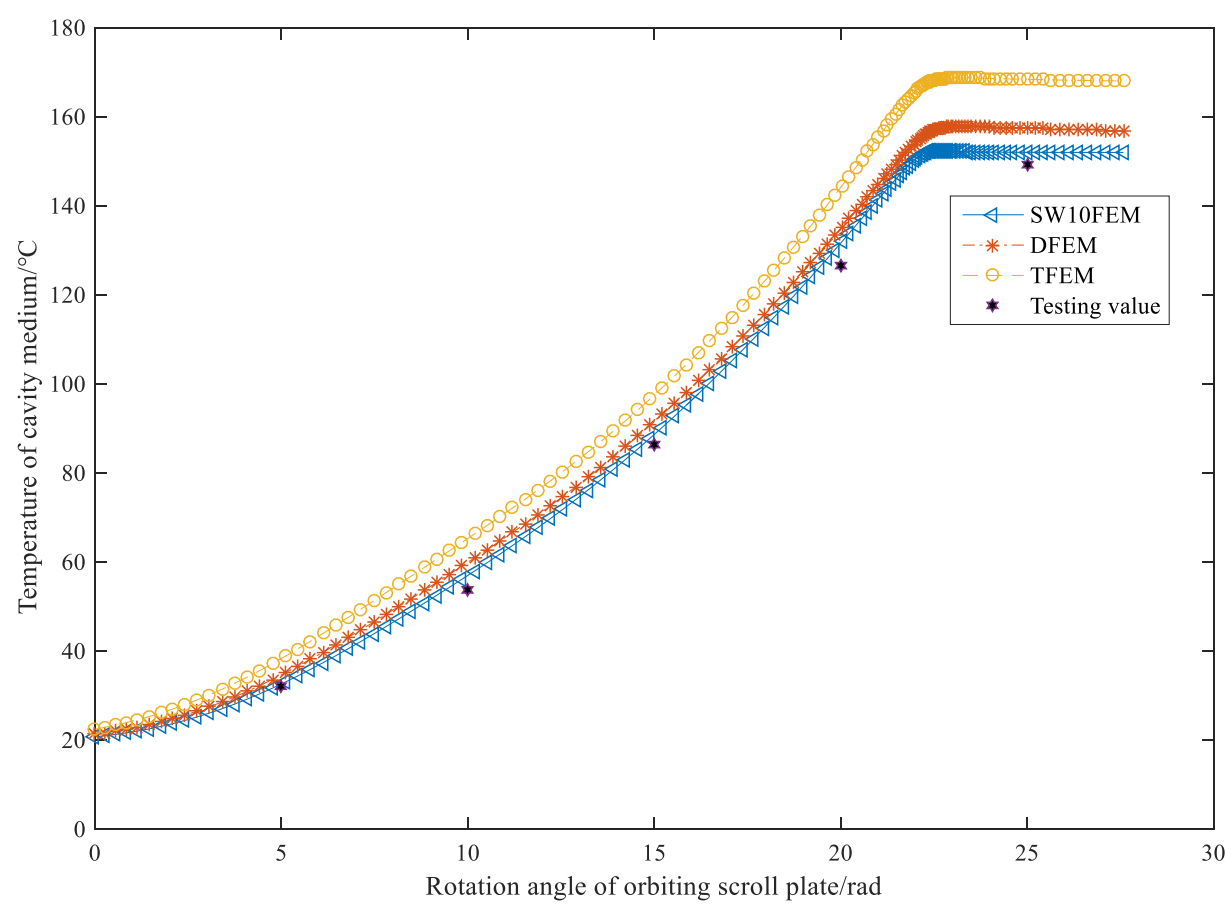

Figure 6 Temperature changing rules of cavity medium of scroll compressor by different methods

The computing efficiency is also an important evaluation index for heat transfer analysis based on Symlet wavelet finite element method, the calculating time of different simulation method is shown in figure 7. 


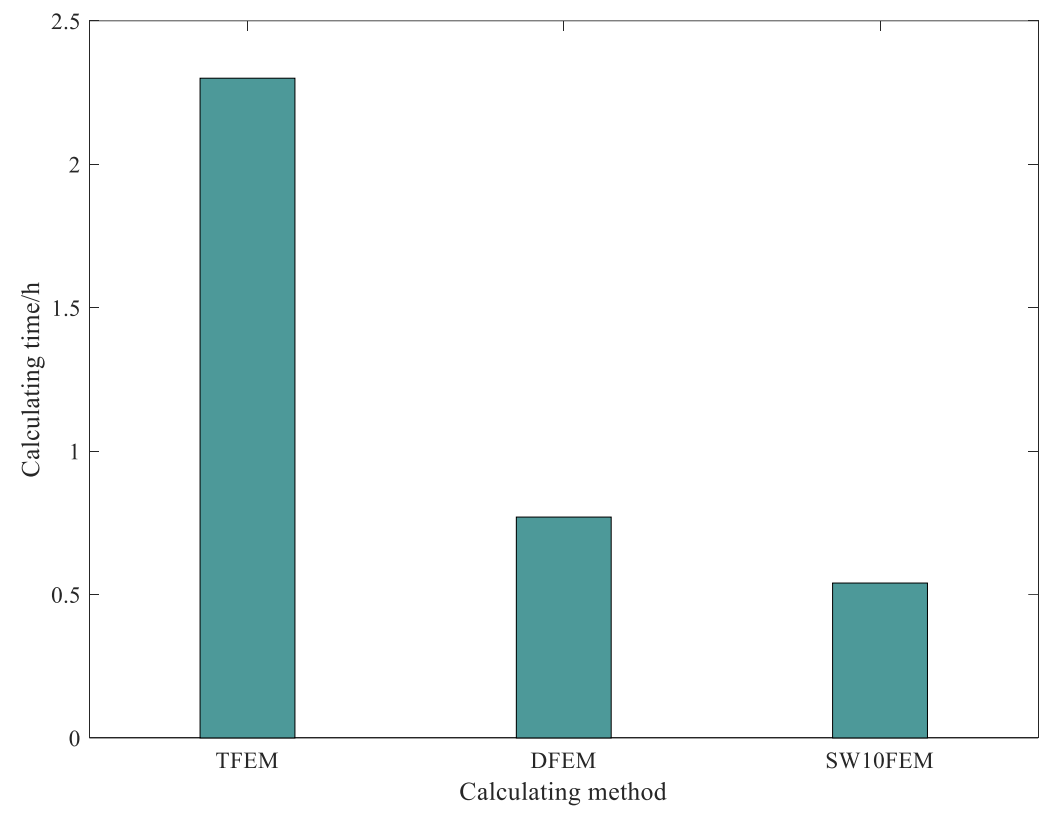

Figure 7 Calculating time of different simulation methods

As seen from figure 7, the calculating time of TFEM is $2.3 \mathrm{~h}$, which is far greater than that of other two methods, the calculating time of SW10FEM is least, which is $0.54 \mathrm{~h}$; The calculating time of DFEM is between that of other two methods. Therefore the Symelet finite element method has highest calculating efficiency, which can save CPU cost.

Heat transfer analysis of cavity medium of scroll compressor with leakage flow and without leakage flow is respectively carried out based on SW10FEM. And the simulation results are shown in figure 8 . As seen from figure 8 , the temperature of cavity medium of scroll compressor with leakage flow is higher than that without leakage flow, The main reason for this lies in that the the gas with high temperature in high-pressure cavity leaks into the cavity with leakage flow, and then the temperature of the cavity medium with leakage flow is higher than that without leakage flow. The cavity medium can also absorb heat from high-pressure cavity through wall of scroll teeth, therefore the temperature of cavity medium will be increased. 


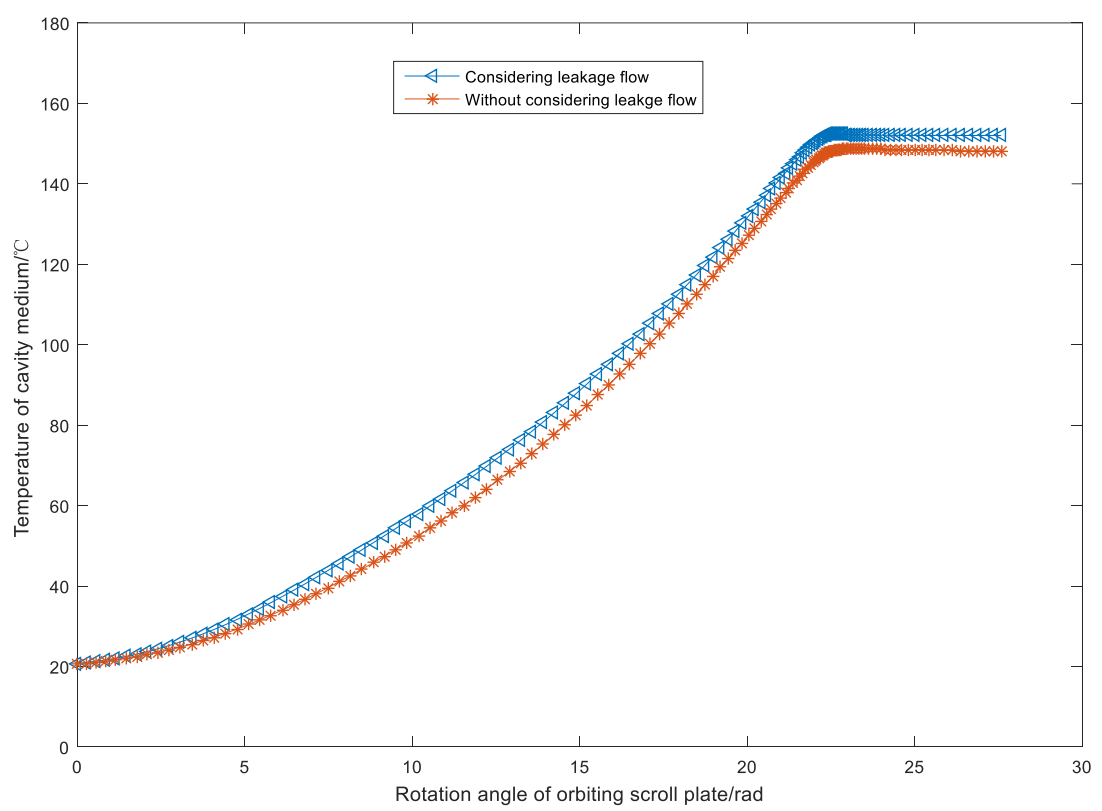

Figure 8 Temperature changing rules of cavity medium considering and without considering leakage flow

The axial meshing clearance and radial meshing clearance can affect the heat transfer performance of cavity medium of scroll, the influences of axial meshing clearance and radial meshing clearance on heat transfer performance are analyzed based on SW10FEM. And the simulation results are shown in figure 9 and figure 10. Figure 9 shows the influences of axis meshing clearance and rotation angle of orbiting scroll plate on temperature of cavity medium of scroll compressor, the temperature of cavity medium of scroll compressor increases with axis clearance, the main reason for this change is that the heat leaking into the low pressure cavity from high pressure cavity increases with increasing of axis meshing clearance. Figure 10 shows the influences of radius meshing clearance and rotation angle of orbiting scroll plate on temperature of cavity medium of scroll compressor, the temperature of cavity medium of scroll compressor also increases with radius meshing clearance, the temperature rising extent of cavity medium due to radius meshing clearance is higher than that due to axis meshing clearance. The most obvious reason for this phenomenon is that the turbulence intensity in radius meshing clearance is higher than that in axis meshing clearance, therefore the velocity gradient of medium in radius meshing clearance is bigger than that in axial meshing clearance. 


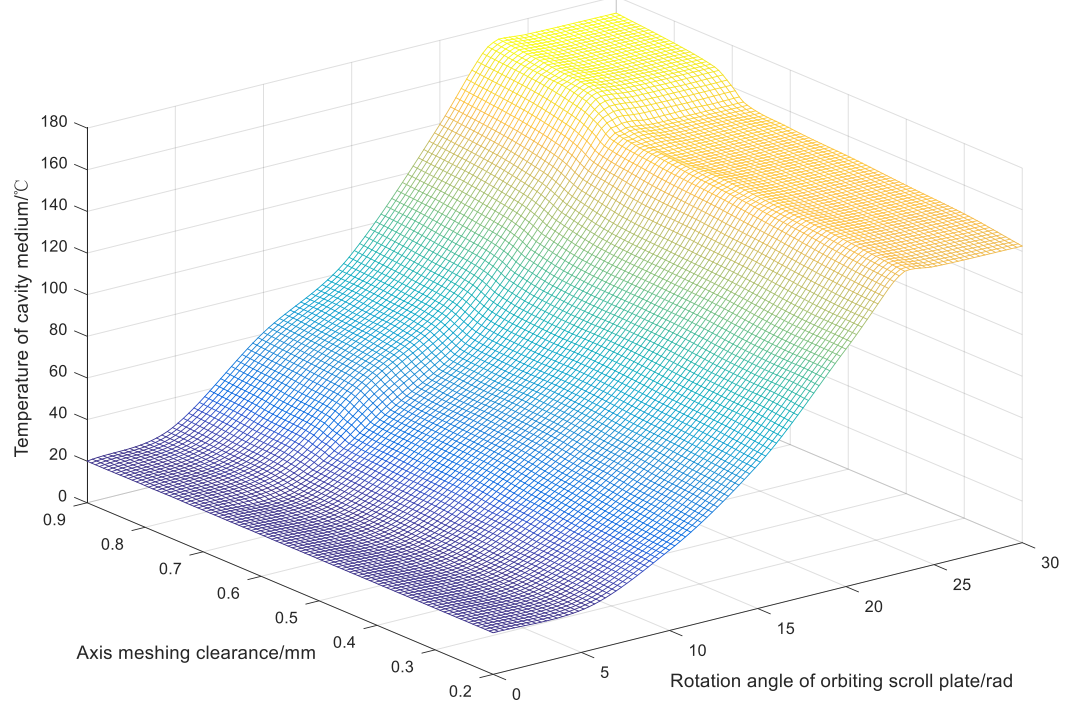

Figure 9 Effect of axial meshing clearance on temperature of cavity medium of scroll compressor

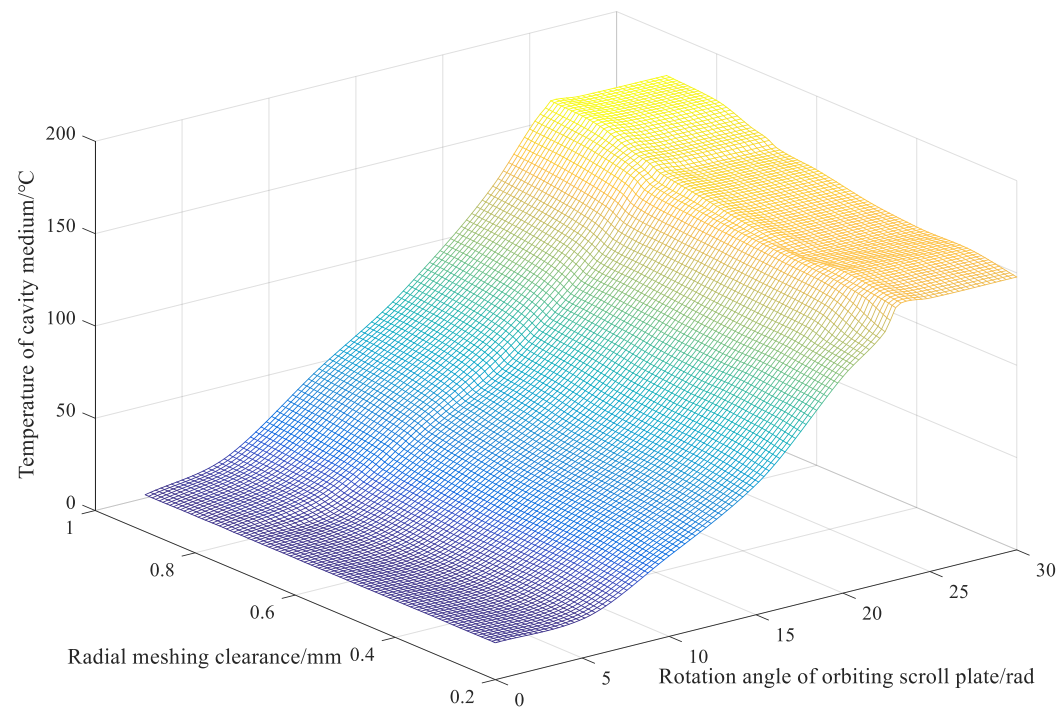

Figure 10 Effect of radial meshing clearance on temperature of cavity medium of scroll compressor

\section{Conclusions}

The heat transfer model of medium in cavity of scroll compressor is established based on large eddy simulation technology considering the leakage flow, and the Symlet wavelet 10 finite element model is constructed using the Symlet wavelet basis function is used as interpolation function to solve the heat transfer model of cavity medium of scroll compressor under leakage flow. The influence mechanism of clearance leakage flow on heat transfer of cavity medium of scroll compressor is revealed based on proposed model. 
Firstly, the Symlet wavelet 10 is selected from Smylet wavelet (1-16) to construct the Symlet wavelet 10 finite element model through comparative analysis of different orders of Symlet wavelets on calculating errors and calculating time. The Symlet wavelet finite element method can obtain the best analysis effect comparing with DFEM and TFEM, which has relatively small calculating errors and calculating time.

Secondly, the heat transfer analysis of cavity medium of scroll compressor with leakage flow and without leakage flow is carried out based on the proposed heat transfer model and SW10FEM, simulation results show that the temperature of cavity medium of scroll compressor with leakage flow is higher than that without leakage flow.

Finally, the influences of axial meshing clearance and radial meshing clearance on heat transfer performance of scroll compressor are analyzed based on the proposed SW10FEM. Results show that the temperature of cavity medium of scroll compressor increases with axis clearance, the temperature of cavity medium of scroll compressor also increases with radius meshing clearance, and the temperature rising extent of cavity medium due to radius meshing clearance is higher than that due to axis meshing clearance.

\section{Availability of data and materials}

All data are fully available without restriction

\section{Authors' contributions}

B is in charge of the model construction, wrote and revised the manuscript. HY takes part in the program design. DK takes part in experiment design and test. LZ takes part in simulation analysis. All authors read and approve the final manuscript.

\section{Authors' information}

Bin Zhao, born in 1978, is currently a Associate professor at Liaoning Shihua university, Fushun, China. He received the M.E. degree in engineering mechanics from China University of Petroleum, Beijing, China. He is current research interests include heat transfer and fluid machinery.

Haoyang Song, born is 1988, is currently a graduate student at Department of Mechanical Engineering, Liaoning Shihua University, China. He is mainly engaged in the mechanical engineering.

Diankui Gao, born in 1975, is currently a experimenter at Department of Mechanical Engineering, he obtained the M.E degree in mechanical engineering from University of Science and Technology Liaoning, Anshan, China. He is mainly engaged in experiment of fluid mechanics.

Lizhi Xu, born in 1967, is current a Associate professor at Liaoning Shihua University, Fushun, China. He received the M.E. degree in chemical machinery from Liaoning Shiua University, Fushun, China. He is currently engaged in Mechanical Engineering.

\section{Funding}

The research is supported by "Scientific Research Funding Project form the Educational Department of Liaoning Province (No. L2019022). "

\section{Competing interests}

The authors declare no competing financial interests.

\section{Author Details}

Department of Mechanical Engineering, Liaoning Shihua University, Liaoning 113001, China. 


\section{References}

[1] Marco C. Diniz, Evandro L.L. Pereira, Cesar J. Deschamps, A lumped-parameter thermal model for scroll compressors including the solution for the temperature distribution along the scroll wraps, International journal of refrigeration, 53(2015), 184-194

[2] Evandro L.L. Pereira, Cesar J. Deschamps, A heat transfer correlation for the suction and compression chambers of scroll compressors, International journal of refrigeration, 82(2017) 325-334

[3] Alireza Zendehboudi, Afshin Tatar, Oil flooded scroll compressors: Predicting the energy performance and evaluating the experimental data, Measurement 112 (2017) 38 - 46

[4] Domenique R. Lumpkin, Ammar M. Bahman, Eckhard A. Groll, Two-phase injected and vapor-injected compression: Experimental results and mapping correlation for a R-407C scroll compressor, International journal of refrigeration, 86(2018) 449-462

[5] Luis Carlos Mendoza, Sylvain Lemofouet, Jürg Schiffmann, Two-phase and oil-free co-rotating scroll compressor/expander, Applied Thermal Engineering 148 (2019) 173-187.

[6] Morini Mirko, Pavan Claudio, Pinelli Michele, Romito Eva, Suman Alessio, Analysis of a scroll machine for micro ORC applications by means of a RE/CFD methodology, Applied Thermal Engineering, 80 (2015) 132-140.

[7] Singh Simarpreet, Singh Abhyuday, Dasgupta M.S., CFD Modeling of a Scroll Work Recovery Expander for Trans-critical CO2Refrigeration System, Energy Procedia, 109(2017) 146-152.

[8] Rak Józef, Pietrowicz Slawomir, Gnutek Zbigniew, 3D numerical calculations of tangent leakages in scroll compressor during unsteady process, Progress in Computational Fluid Dynamics, 17(6) (2017) 344-351.

[9] Burmistrov A., Salikeev S., Raykov A., Fomina M., Mathematical model of working process of oil free scroll vacuum pump: Influence of leakage and heat transfer on pumping characteristics, Vakuum in Forschung und Praxis, 29(6) (2017) 28-31.

[10] Mendoza Luis Carlos, Lemofouet Sylvain, Schiffmann Jürg, Testing and modelling of a novel oil-free co-rotating scroll machine with water injection, Applied Energy, 185(2017) 201-213.

[11] Fábio M.Bayer, Alice J.Kozakevicius, Renato J.Cintra, An iterative wavelet threshold for signal denoising, Signal Processing, 162(9) (2019) 10-20.

[12] Mariantonia Cotronei, Milvia Rossini, Tomas Sauer, Elena Volontè, Filters for anisotropic wavelet decompositions, Journal of Computational and Applied Mathematics, 149(3) (2019) 316-330.

[13] Max Budninskiy, Houman Owhadi, Mathieu Desbrun, Operator-adapted wavelets for finite-element differential forms, Journal of Computational Physics, 388(7) (2019) 144-177.

[14] Musuva Mutinda, Mares Cristinel, The wavelet finite element method in the dynamic analysis of a functionally graded beam resting on a viscoelastic foundation subjected to a moving load, European Journal of Computational Mechanics, 24(5) (2015) 171-209.

[15] Mokhtari Ali, Mirdamadi Hamid Reza, Ghayour Mostafa, Wavelet-based spectral finite element dynamic analysis for an axially moving Timoshenko beam, Mechanical Systems and Signal Processing, 92(2017) 124-145.

[16] Khalili Ashkan, Jha Ratneshwar, Samaratunga Dulip, The Wavelet Spectral Finite Element-based user-defined element in Abaqus for wave propagation in one-dimensional 
composite structures, Simulation, 93(5) (2017) 397-408.

[17] Samaratunga Dulip, Jha Ratneshwar, Gopalakrishnan Sirinivasan, Wavelet spectral finite element for modeling guided wave propagation and damage detection in stiffened composite panels, Structural Health Monitoring, 15(3) (2016) 317-334.

[18] Azdoud Yan, Cheng Jiahao, Ghosh Somnath, Wavelet-enriched adaptive crystal plasticity finite element model for polycrystalline microstructure, Computer Methods in Applied Mechanics and Engineering, 327(2017) 36-57.

[19] Ashory Mohammad-Reza, Ghasemi-Ghalebahman, Ahmad;Kokabi, Mohammad-Javad, Damage identification in composite laminates using a hybrid method with wavelet transform and finite element model updating, Proceedings of the Institution of Mechanical Engineers, Part C: Journal of Mechanical Engineering Science, 232(5) (2018) 815-827.

[20] Dhend Mangal Hemant and Chile Rajan Hari, Fault Diagnosis of Smart Grid Distribution System by Using Smart Sensors and Symlet Wavelet Function, Journal of Electronic Testing: Theory and Applications (JETTA), 33(3) (2017) 329-338.

[21]Kodjo Apelete Raoul Kpegli, Sjoerd E. A. T. M. van der Zee, Abdoukarim Alassane, George Bier, Daouda Mama, Impact of hydraulic and storage properties on river leakage estimates: A numerical groundwater flow model case study from southern Benin, Journal of Hydrology: Regional Studies, 19(2018) 136-163.

[22] Edward Canepa, Andrea Cattanei, Fabio Mazzocut Zecchin, Davide Parodi, Large-scale unsteady flow structures in the leakage flow of a low-speed axial fan with rotating shroud, Experimental Thermal and Fluid Science, 102 (2019) 1-19.

[23] Seyfoddin Mojallal Agh, Jamasb Pirkandi, Mostafa Mahmoodi, Mehdi Jahromi, Optimum design, simulation and test of a new flow control valve with an electronic actuator for turbine engine fuel control system, Flow Measurement and Instrumentation, 65(2019) 65-77.

[24] Martin Draksler, Boštjan Končar, Leon Cizelj, On the accuracy of Large Eddy Simulation of multiple impinging jets, International Journal of Heat and Mass Transfer, 133(2019) 596-605.

[25] Mario Rüttgers, Junshin Park, Donghyun You, Large-eddy simulation of turbulent flow over the DrivAer fastback vehicle model, Journal of Wind Engineering and Industrial Aerodynamics, 186(2019) 123-138.

[26] Mahdi Saeedipour, Stéphane Vincent, Stefan Pirker, Large eddy simulation of turbulent interfacial flows using Approximate Deconvolution Model, International Journal of Multiphase Flow, 112(2019) 286-299.

[27] Ashley Brereton, Andrés E. Tejada-Martínez, Matthew R. Palmer, Jeff A. Polton, The perturbation method - A novel large-eddy simulation technique to model realistic turbulence: Application to tidal flow, Ocean Modelling, 135(2019) 31-39.

[28] Marcin Pilarczyk and Bohdan Węglowski, Determination and validation of transient temperature fields within a cylindrical element using the inverse heat conduction method, Applied Thermal Engineering, 150(2019) 1224-1232.

[29] Ravinder Kumar and Hari Om Bansal, Hardware in the loop implementation of wavelet based strategy in shunt active power filter to mitigate power quality issues, Electric Power Systems Research, 169(2019) 92-104.

[30] Jake D. Campbell, Christopher G. Pretty, J. Geoffrey Chase, Phillip J. Bones, Near-Real-Time Detection of Pulse Oximeter PPG Peaks Using Wavelet Decomposition, IFAC-PapersOnLine, 51(2018) 146-151. 
[31] Ritu Singh, Rajesh Mehta, Navin Rajpal, Efficient wavelet families for ECG classification using neural classifiers, Procedia Computer Science, 132(2018) 11-21.

[32] Petr Sváček, Numerical simulation of fluid-structure interactions with stabilized finite element method, Advances in Engineering Software, 113(2017) 96-107.

[33] Hermí nio T. Honório, Clovis R. Maliska, Massimiliano Ferronato, Carlo Janna, A stabilized element-based finite volume method for poroelastic problems, Journal of Computational Physics, 364(2018) 49-72.

[34] Gabriel J. Lord and Antoine Tambue, Stochastic exponential integrators for a finite element discretisation of SPDEs with additive noise, Applied Numerical Mathematics, 136(2019) 163-182.

[35] S. Busto, J. L. Ferrín, E. F. Toro, M. E. Vázquez-Cendón, A projection hybrid high order finite volume/finite element method for incompressible turbulent flows, Journal of Computational Physics, 353(2018) 169-192. 
Figures

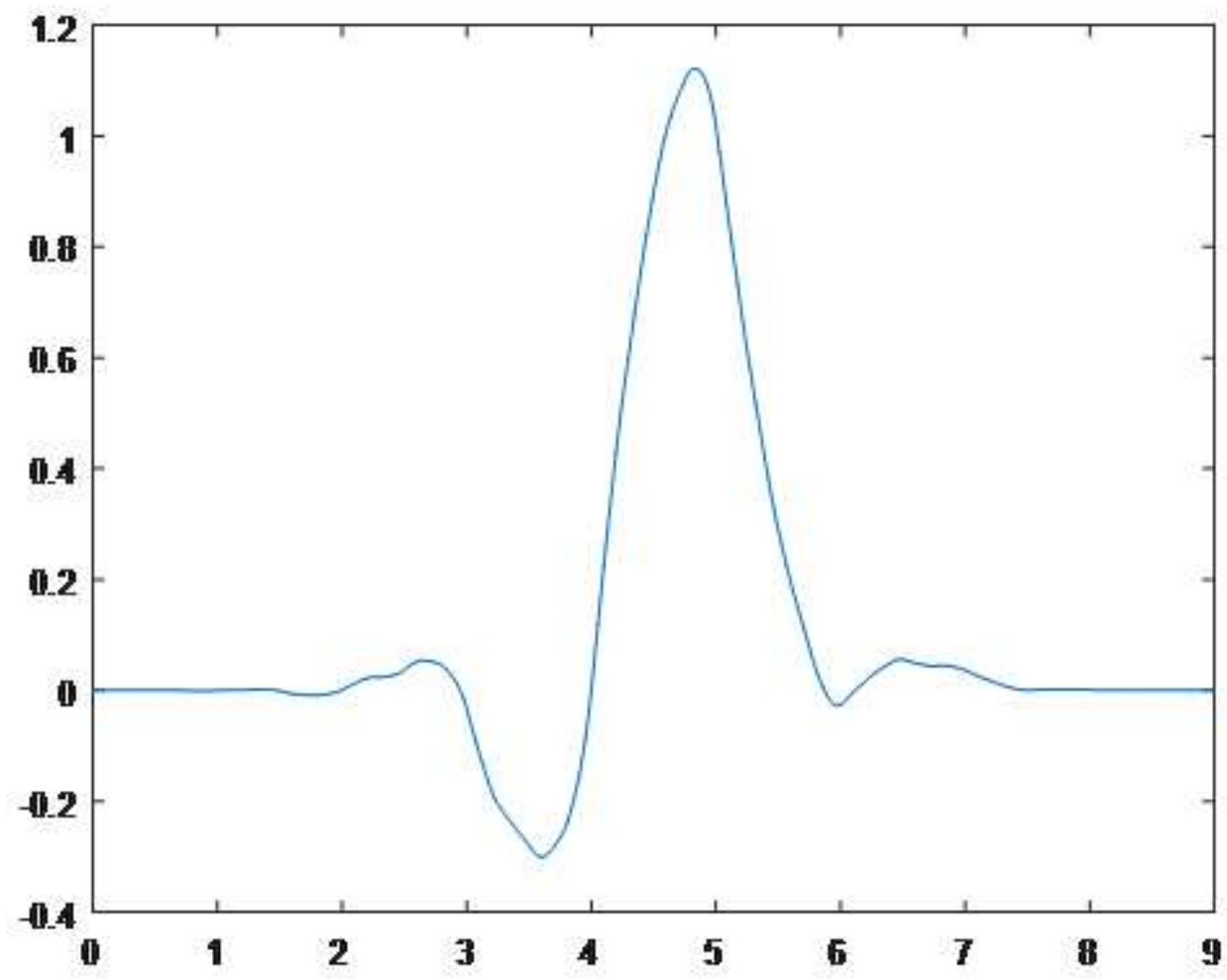

Figure 1

Symlet wavelet function 


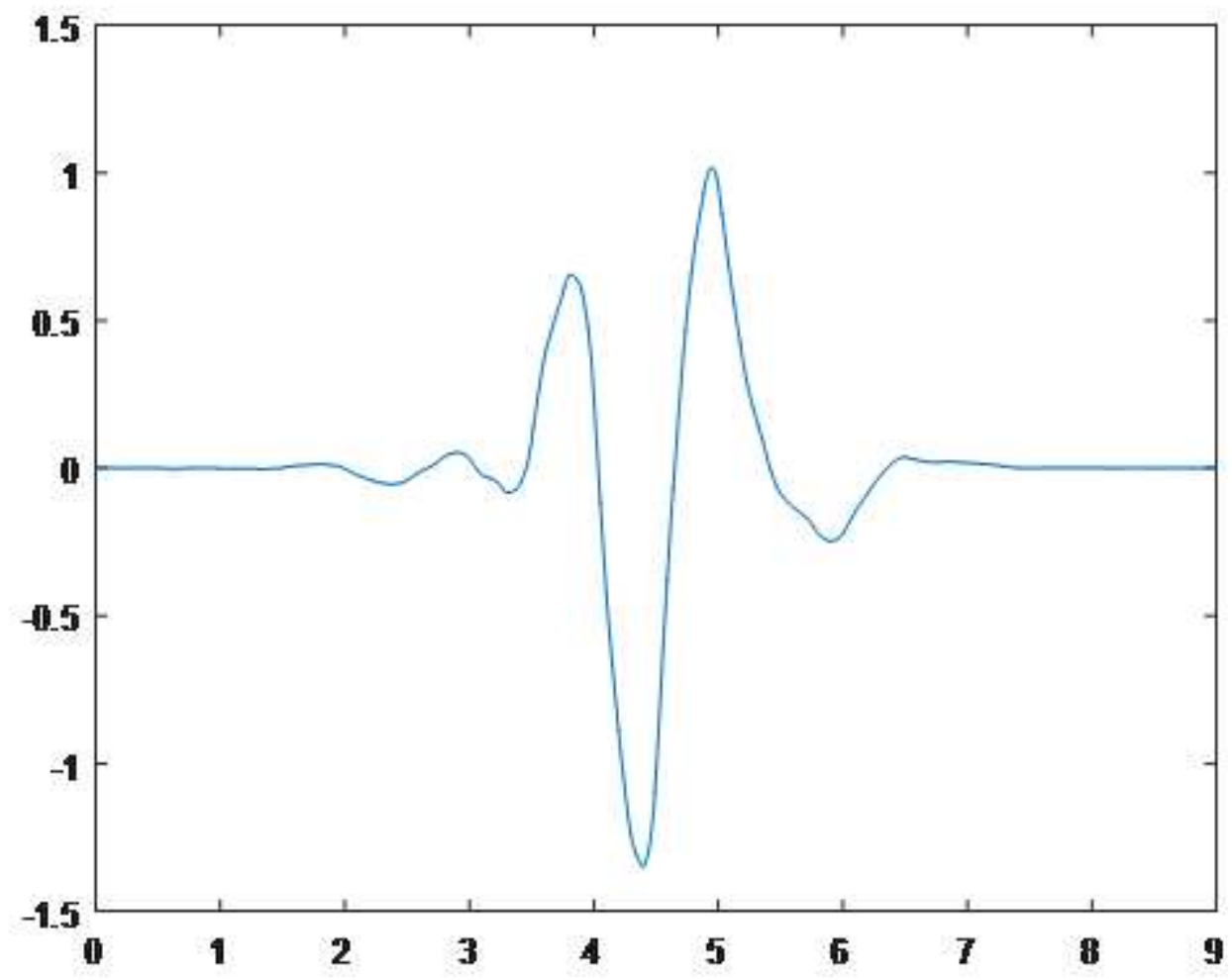

Figure 2

Symlet wavelet scale function
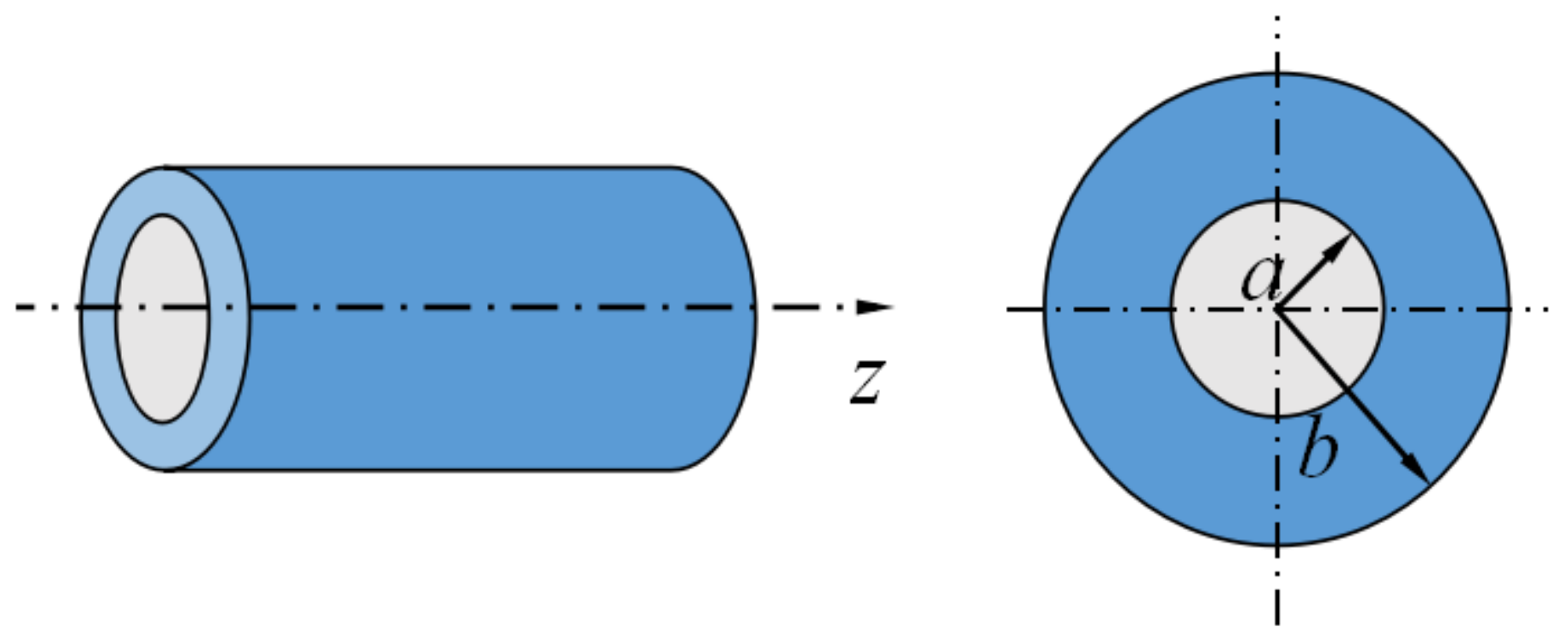

Figure 3

Diagram of cylinder 


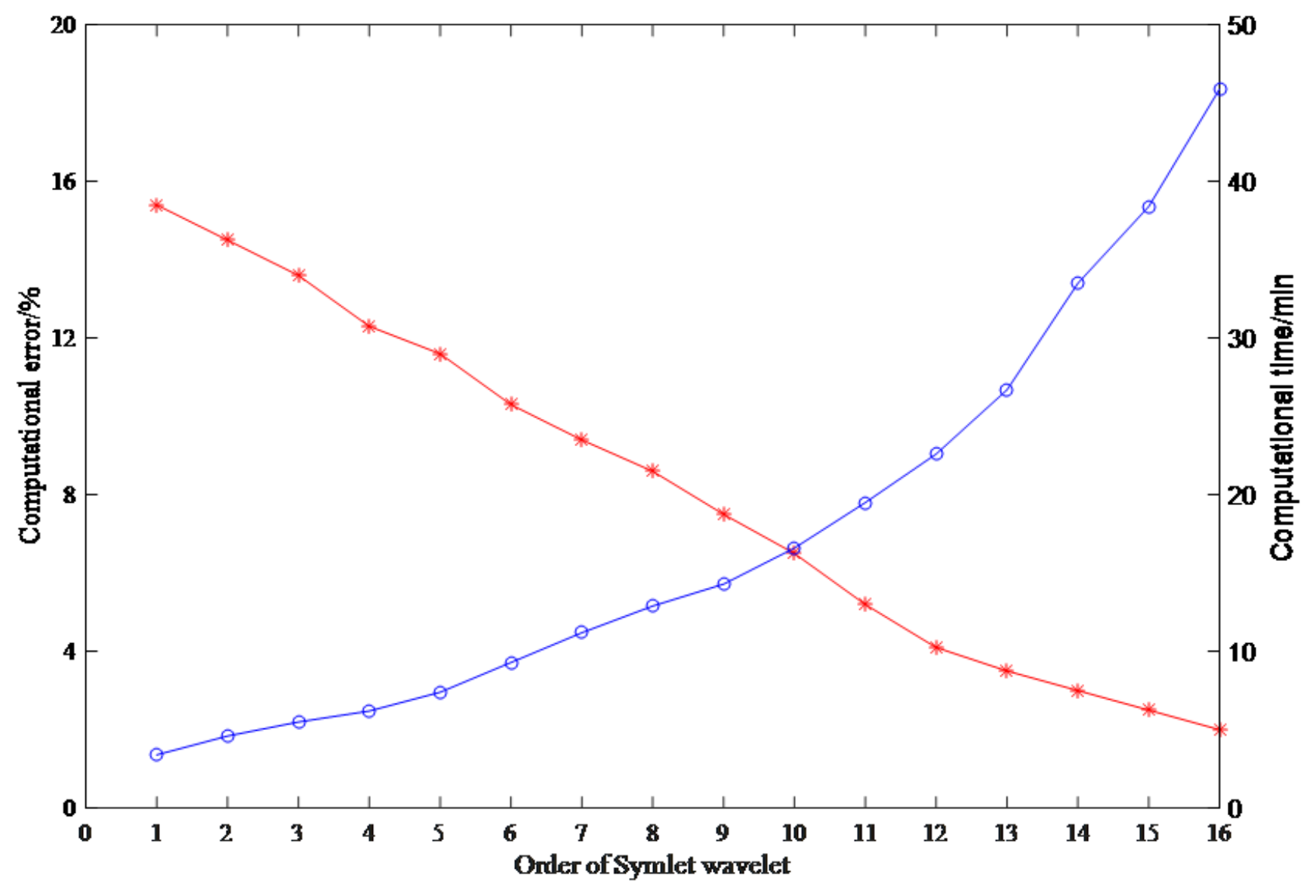

Figure 4

Computational error and time of different Symlet wavelet function

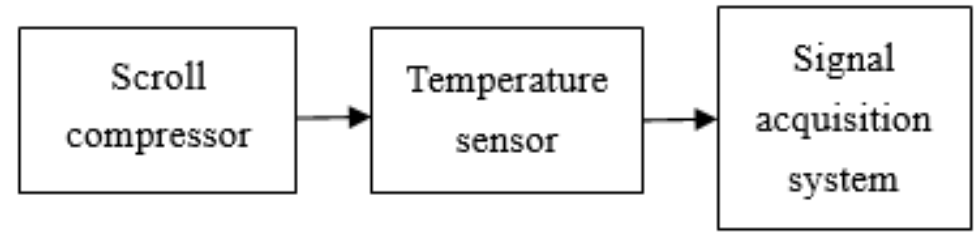

Figure 5

Temperature testing system of scroll compressor 


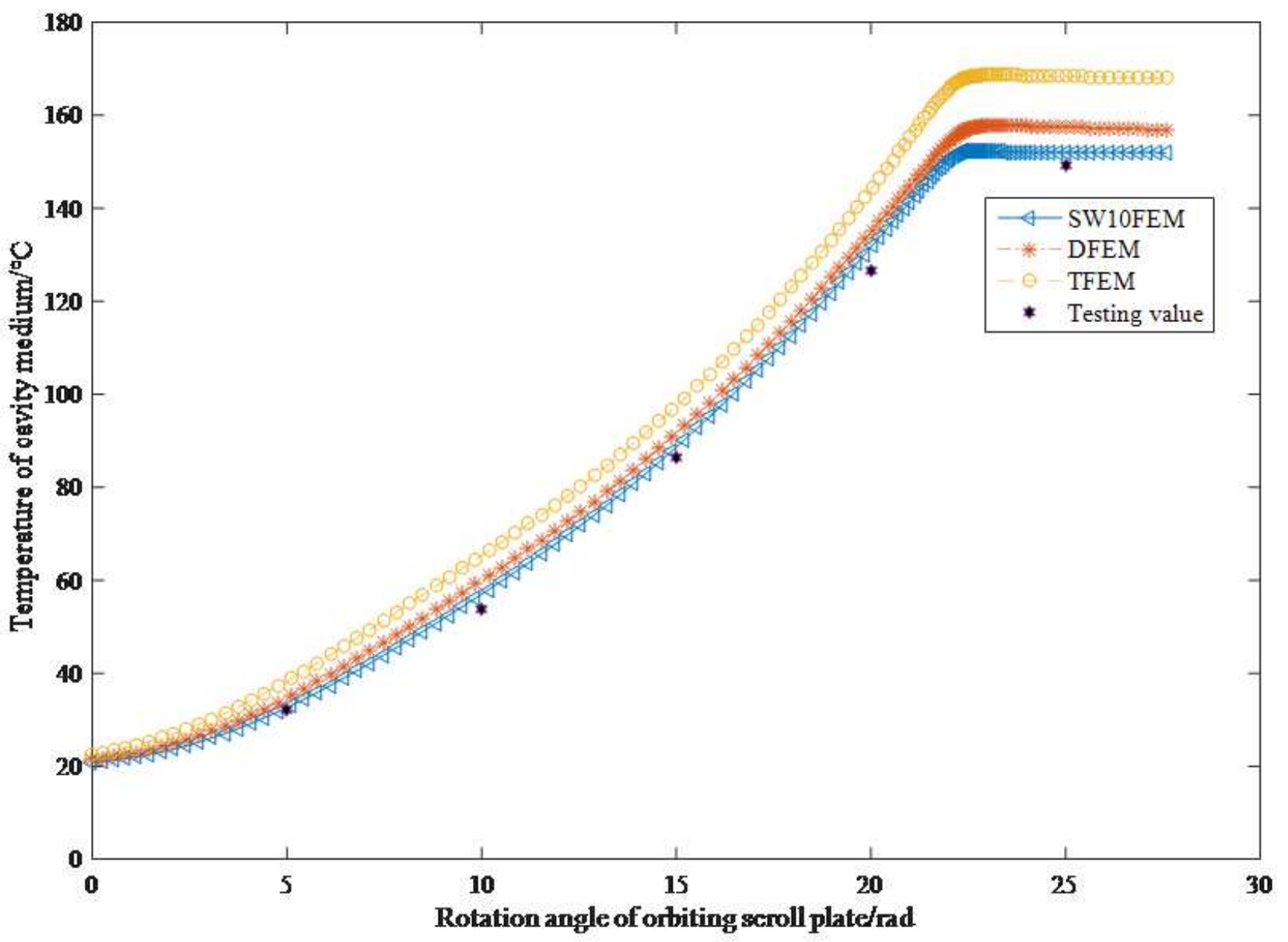

Figure 6

Temperature changing rules of cavity medium of scroll compressor by different methods 


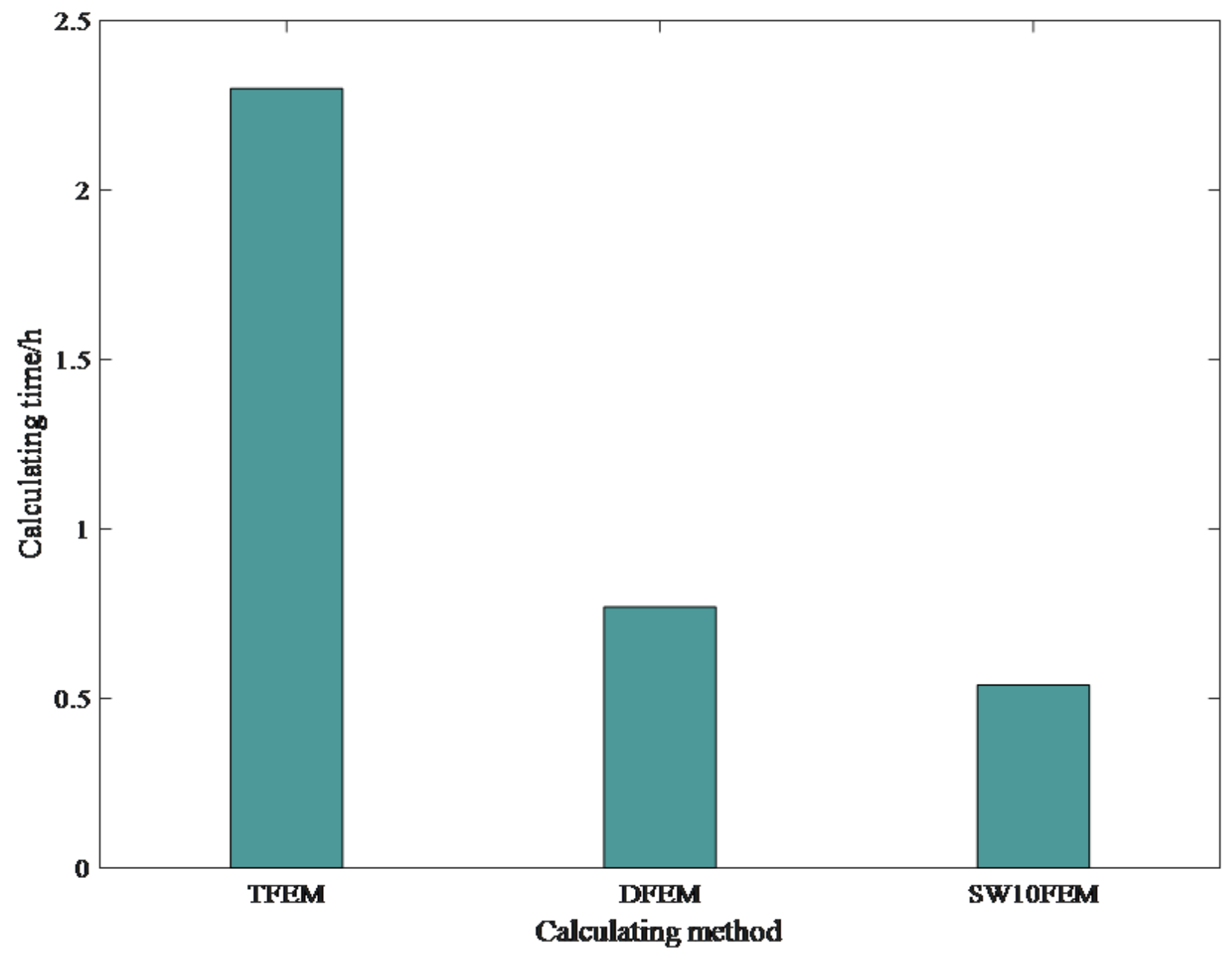

Figure 7

Calculating time of different simulation methods 


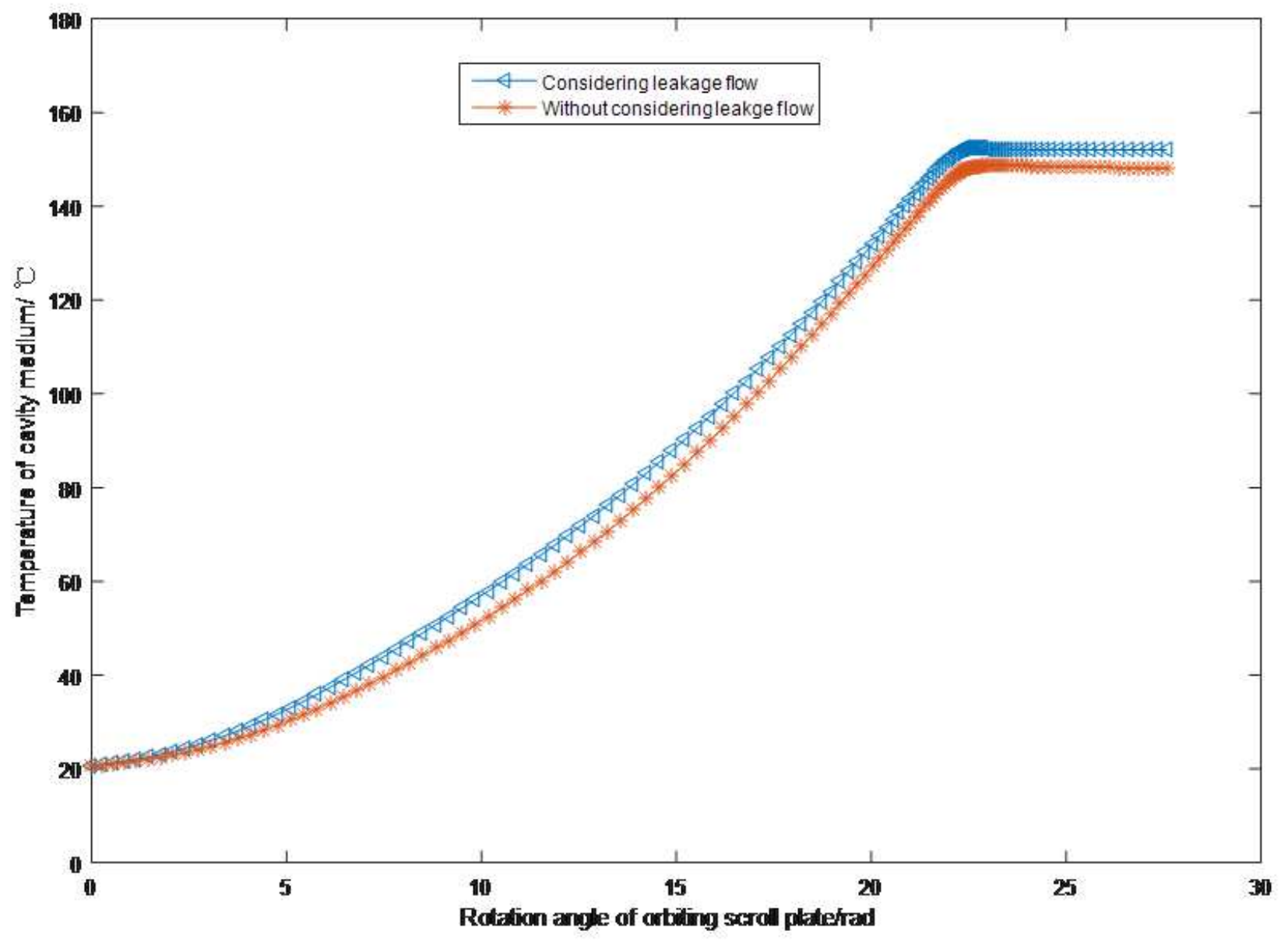

Figure 8

Temperature changing rules of cavity medium considering and without considering leakage flow 


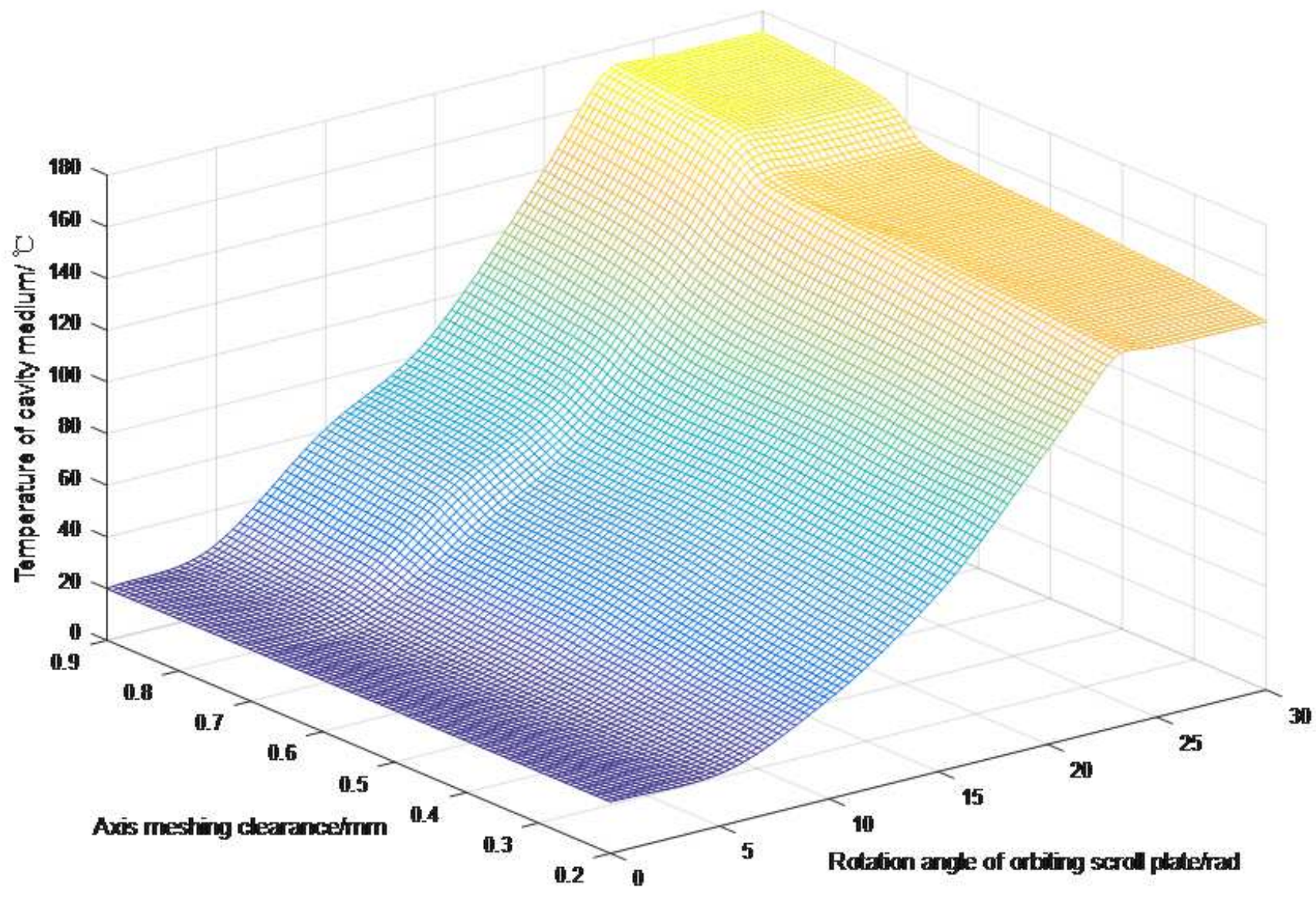

Figure 9

Effect of axial meshing clearance on temperature of cavity medium of scroll compressor 


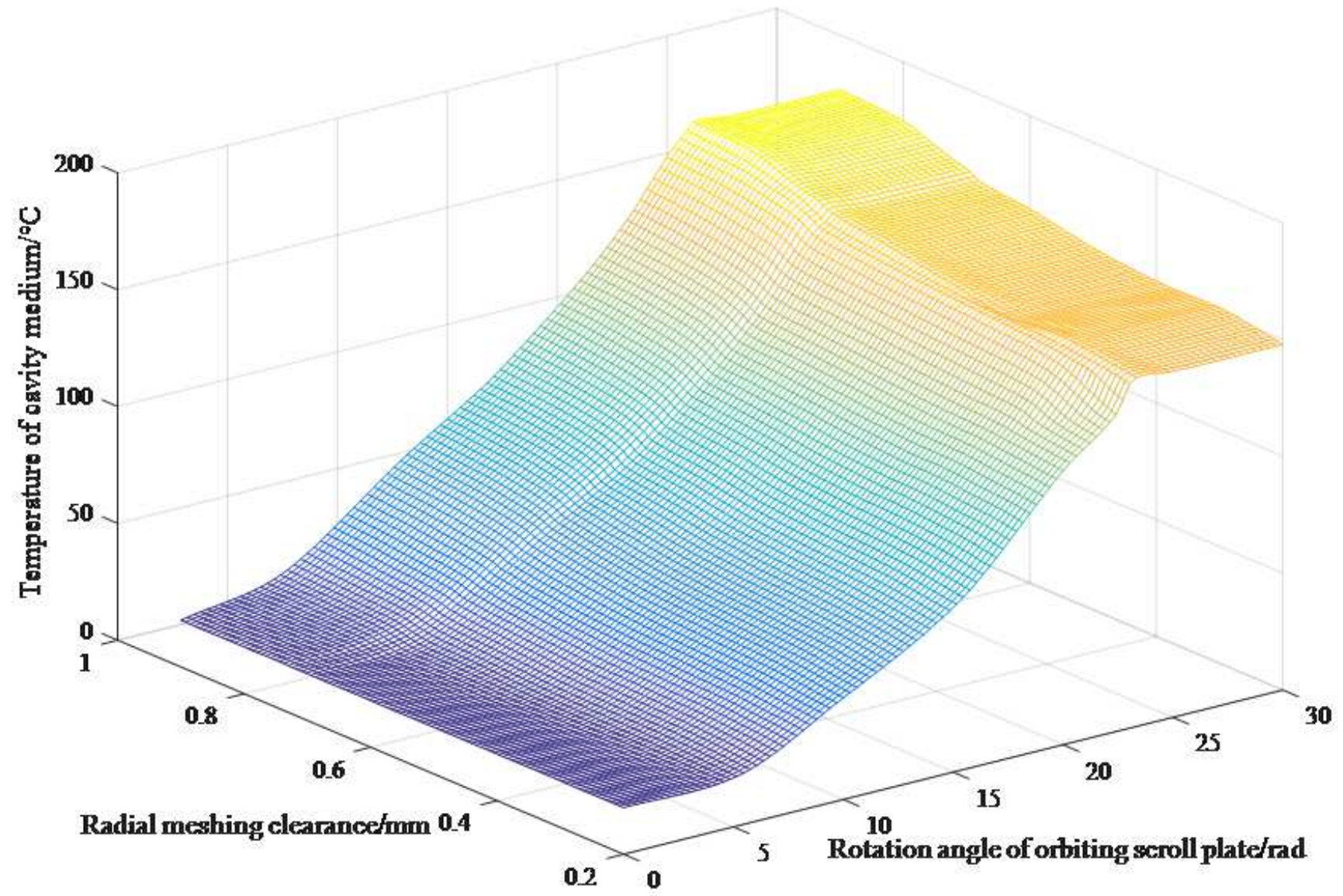

Figure 10

Effect of radial meshing clearance on temperature of cavity medium of scroll compressor 